\title{
La recepción del Vaticano II en la Iglesia salvadoreña
}

\author{
Rodolfo Cardenal, \\ Instituto de Historia de Nicaragua y Centroamérica, \\ UCA, Managua \\ Departamento de Teología, \\ UCA, San Salvador
}

La Iglesia salvadoreña recibe el Vaticano II hasta cinco años después de concluido el concilio. Algo parecido ocurre con Medellín, recibido dos años después de su terminación. El retraso solo se explica por el desconocimiento y el desinterés de la Iglesia salvadoreña. Más aún, las primeras reacciones presentan un tenaz rechazo a este magisterio de la Iglesia universal y regional por la mayoría del episcopado, de la inmensa mayoría del clero y la vida consagrada, y de la elite intelectual católica. La Iglesia salvadoreña se encuentra con el Vaticano II y Medellín y sus consecuencias pastorales en la primera semana de pastoral de conjunto, realizada a mediados de 1970, pero no por eso los acepta oficialmente.

Los argumentos para rechazar este magisterio aparecen en los acontecimientos suscitados alrededor de esa primera semana. Estos evidencian una Iglesia fundamentalmente tradicionalista e identificada con la oligarquía y los militares salvadoreños. Por otro lado, el sector que impulsaba la aceptación del Vaticano II y de Medellín había optado por la liberación del pueblo salvadoreño. Es un sector eclesial donde se destacan los sacerdotes jóvenes con una buena formación, muy activos y entusiastas, y deseosos de responder al desafío de una realidad nacional opresiva e injusta. Uno de los representantes más destacados de este sector es el jesuita Rutilio Grande, asesinado el 12 de marzo de 1977, por esas mismas fuerzas aliadas del sector tradicionalista de la Iglesia. Él es la fuente primordial para esta aproximación a la recepción del Vaticano II y Medellín. La mayor parte de la información que utilizo proviene de su archivo 
personal, conservado en el archivo histórico de la Provincia Centroamericana de la Compañía de Jesús, y de su biografía ${ }^{1}$.

\section{La primera semana de pastoral de conjunto}

La primera semana de pastoral de conjunto reúne a 83 sacerdotes, 30 religiosas, dos religiosos, 32 seminaristas y 38 seglares, del 22 al 26 de junio de 1970. La semana es pensada como un espacio para la búsqueda y la interpelación con la ayuda del método "ver, juzgar y actuar", muy en boga en América Latina en la década de 1970. En consecuencia, el punto de partida de la semana es la realidad humana y eclesial salvadoreña, la cual es juzgada a la luz del Vaticano II y Medellín. Desde ese juicio se cuestiona la vocación humana y la misión eclesial, y se lanzan líneas pastorales para orientar la práctica eclesial. No obstante el peligro de inmediatismo, la dirección de la semana renuncia a proponer esquemas preconcebidos, pues le interesa más que los participantes se expresen con franqueza y libertad ${ }^{2}$.

La semana es presidida por el obispo auxiliar de San Salvador y presidente de la comisión de pastoral de la conferencia episcopal, Mons. Arturo Rivera, y es dirigida por el secretario ejecutivo del Departamento de Pastoral de la Conferencia Episcopal Latinoamericana (Celam), Edgard Beltrán, con la asistencia de los sacerdotes Freddy Delgado (liturgia), Ricardo Urioste (prensa) y Juan R. Vega (secretaría general). Según la metodología adoptada, la exposición magistral alimenta la discusión de quince mesas de trabajo heterogéneas, cuyas reflexiones son compartidas luego en asamblea plenaria ${ }^{3}$.

Pese al empeño de los organizadores por conseguir una elevada participación, la respuesta es, en sí misma, desconcertante. La arquidiócesis es la más representada -60 sacerdotes, dos religiosos, 20 religiosas y 23 seglares. La diócesis de Santa Ana está representada por diez sacerdotes y una religiosa. La de San Miguel por seis sacerdotes y un seglar. La de San Vicente por cinco sacerdotes y nueve seglares, y la de Santiago de María por dos sacerdotes. La respuesta de los movimientos seglares es muy baja, pese a que sus dirigentes fueron invitados personalmente por los organizadores y los asesores eclesiásticos. La baja asistencia de la vida consagrada al parecer se explica porque la semana coincide con la actividad escolar, a la cual se dedica la mayoría de congregaciones e institutos. Estas se conformaron con enviar a uno o dos representantes. La Compañía

1. R. Cardenal, Historia de una esperanza. Vida de Rutilio Grande. San Salvador: UCA Editores, 1985.

2. Actas de la Primera Semana de Pastoral de Conjunto en El Salvador, 22-26 de junio de 1970.

3. Ibidem; J. Llasera, "Crónica de El Salvador. Semana de Pastoral de Conjunto", ECA 262 (1970), p. 393. 
de Jesús no es la excepción. Aparte de Rutilio Grande, que participó plenamente, unos cuantos jesuitas asisten de manera irregular. Los dos grupos más activos y entusiastas de la semana fueron los jóvenes, tanto sacerdotes como religiosos y religiosas, en su mayoría, de la arquidiócesis. En las mesas de trabajo se destacaron los seminaristas y los universitarios de la pastoral juvenil ${ }^{4}$.

La ausencia más notable fue la del episcopado, es decir, la instancia que había convocado la semana. Excepto el arzobispo, Mons. Luis Chávez, y Mons. Rivera, los demás obispos participaron de forma bastante irregular. El segundo día de la semana, la asamblea acuerda reiterarles, por medio de un telegrama, su deseo de compartir con ellos sus reflexiones. Pero Mons. Romero, recién consagrado obispo auxiliar de San Salvador, presente en el plenario, objetó que sería improcedente, porque la conferencia episcopal había convocado a la semana y esta ya contaba con la presencia de Mons. Rivera. Un telegrama, advierte Mons. Romero, lastimaría la susceptibilidad episcopal y daría pie a malas interpretaciones. Varias voces contradijeron su opinión con el argumento de que la presencia del episcopado era necesaria, porque los obispos son los primeros responsables de la pastoral y porque luego no comprenderían las conclusiones, las sacarían de contexto, las malinterpretarían y paralizarían el proceso de aggiornamento, precisamente, lo que en efecto sucedió. Una nueva votación aprobó por unanimidad enviar el siguiente texto: "Ciento veintitrés laicos, religiosas y sacerdotes de ambos cleros echamos de menos a su Excelencia Jornada Nacional de Pastoral. Su presencia sería de gran ayuda para descubrir y realizar Pastoral adecuada nuestro tiempo. Respetuosamente. Participantes Semana Nacional de Pastoral". El obispo de San Vicente (Mons. Pedro Aparicio) respondió que no asistiría para no encontrarse con sacerdotes sin traje talar y el de Santiago de María (Mons. Jorge Castro Ramírez) dijo que tampoco asistiría para atender las parroquias abandonadas por sus dos sacerdotes. El obispo de San Miguel (Mons. José Eduardo Álvarez) no respondió. Solo el de Santa Ana (Mons. Benjamín Barrera), aparte de los tres de la arquidiócesis, asistió a unas cuantas sesiones ${ }^{5}$.

La asamblea también cuestionó la integración de la comisión encargada de redactar el documento final - los sacerdotes Inocencio Alas y C. Villacorta, Madre Felicita y los seglares Ana María Romero y Manuel Batres - porque, a su juicio, habían sido nombrados de manera autoritaria. Entonces, Mons. Rivera intervino para asumir la responsabilidad por tales nombramientos y explicó que el criterio utilizado no había sido pastoral o teológico, sino la capacidad y la eficiencia. El plenario rechazó la renuncia de la comisión y se limitó a ampliarla con dos sacerdotes, un religioso (Rutilio Grande), una religiosa y un seglar.

4. Ibidem.

5. Ibidem. 
La realidad nacional es expuesta por Héctor Dada — presidente de Acción Católica Universitaria Salvadoreña (ACUS), 1959-1963, miembro permanente del Secretariado Latinoamericano Pax Romana (1963), cofundador de Pax Romana de El Salvador (1967), diputado del Partido Demócrata Cristiano (19661968, 1968-1970) y miembro del concejo municipal de San Salvador (1970)—, desde la teoría de la dependencia, muy en boga en esos años. Beltrán explica la realidad eclesial con la contraposición de dos tipos de misión. El primero está satisfecho con lo que sabe y hace, y, en consecuencia, se concentra en aumentar la cantidad de sacramentos administrados. Por lo tanto, no está interesado en cambiar y siempre encuentra excusas para no renovar. En cambio, el otro tipo se mantiene en actitud de búsqueda y diálogo, y en un proceso continuo de conversión. La exposición del secretario ejecutivo de la Celam la completa Rosendo Manzanares - militante de ACUS, secretario latinoamericano de Pax Romana-MIEC (1968-1970) y también miembro del concejo municipal de San Salvador- con un análisis estadístico de la vida religiosa del país. Las mesas de trabajo y el plenario concluyen que hasta entonces la pastoral había enfatizado más la salvación individual que la liberación personal integral, que la catequesis había insistido más en la doctrina que en cultivar la fe, que la liturgia había caído en el ritualismo desmedido con menoscabo de la formación de la comunidad cristiana y que la Iglesia estaba en connivencia tácita con la clase dominante en detrimento del compromiso evangélico con la justicia, por miedo a perder privilegios y sufrir persecución ${ }^{6}$.

La segunda parte de la semana la introduce Beltrán, quien llama la atención sobre la novedad del Vaticano II y la necesidad de una teología que responda a la realidad salvadoreña. Fundamenta su argumentación en Gaudium et spes, en la responsabilidad histórica en la construcción del Reino de Dios y en los diversos tipos de conciencia, según el pensamiento de Paulo Freire. Ignacio Ellacuría completa su exposición con el carisma y la misión de la Iglesia latinoamericana, entendidos como salvación del pecado objetivado en una estructura social, fundamentada en la propiedad privada y el afán de lucro y, en cuanto tal, responsable de una situación injusta y de la violencia institucionalizada ${ }^{7}$.

En la última parte de la semana, después de la exposición de Beltrán, comisiones sectoriales y el plenario sacan conclusiones pastorales. La asamblea se organiza en dos grandes sectores, el rural (moderado por Rutilio Grande) y el urbano. Cada uno se subdivide en comisiones de fe y evangelización, pastoral de líderes, pastoral juvenil, promoción social, medios de comunicación social, educación, liturgia, parroquia, ministerios, religiosos y pastoral de conjunto. Algunas de ellas - escuela, parroquia y vida consagrada rurales - no se integran

6. Actas de la Primera Semana, op. cit.

7. Ibidem. 
por falta de interesados, lo cual evidencia dónde se encontraba el énfasis de la pastoral. Otras, en cambio - medios de comunicación social, liturgia, ministerios y pastoral de conjunto-, se fusionan por razones prácticas. Mons. Chávez forma parte de la comisión de parroquia urbana, Mons. Rivera de la de pastoral de conjunto, Mons. Barrera de la de fe y evangelización, y el nuncio de la de ministerios. Mons. Romero se abstiene. La comisión de redacción recoge el aporte de las comisiones y elabora el documento final con las conclusiones.

\section{La intervención de la conferencia episcopal y de Roma}

La conferencia episcopal declara inaceptables varias de las conclusiones el 23 de julio de 1970, por considerarlas contrarias a la ortodoxia, la disciplina y la institucionalidad eclesiástica. Los obispos encomiendan a Mons. Romero (secretario de la conferencia) y a Mons. Rivera y tres sacerdotes (José López Sandoval, Martín Barraza y Gregorio Rosa) revisar el documento final y reelaborarlo, de acuerdo a sus observaciones. De esta manera, el 21 de octubre, la conferencia episcopal promulga las "Conclusiones de la Primera Semana de Pastoral de Conjunto en El Salvador. 26 de junio de 1970. Esquema para una Pastoral de Conjunto". El documento es promulgado por "la Conferencia Episcopal de El Salvador, después de haber oído el parecer de prudentes sacerdotes, religiosos y laicos", en lugar del "Nosotros, la Iglesia de El Salvador" original. De todas maneras, los obispos se pronunciaron sin haber participado en la semana, sin haber asistido a sus deliberaciones y sin escuchar la opinión de sus respectivas diócesis.

Las "conclusiones" de la conferencia episcopal desautorizan las de la asamblea pastoral. El documento episcopal suprime las formulaciones más radicales y la dimensión profética. Así, la solemne declaración inicial del documento de la asamblea, "Nosotros, la Iglesia en El Salvador, seglares, religiosos y religiosas, sacerdotes y obispos, nos comprometemos a configurar en el país una Iglesia renovada que sea comunidad de amor, servidora de la comunidad humana salvadoreña y que prefigure la comunidad eterna", es reemplazado por un escueto "a la luz de la reflexión de esta Primera Semana de Pastoral de Conjunto". Por lo tanto, el cuestionamiento de la misión de la Iglesia de la primera es reemplazado por una simple "reflexión" episcopal. Donde la asamblea niega con un "no hay", los obispos ponen en duda con un ambiguo "tal vez". La denuncia de una evangelización incompleta por no haber buscado la liberación integral y por reducirse a la interioridad y la trascendencia, es sustituida por una declaración triunfalista, que la da por concluida, aunque sin juzgarla perfecta, pese a los esfuerzos de los obispos. El señalamiento de la concentración de la catequesis en los menores de edad es reemplazado por una afirmación optimista que se limita a pedir que sea más vital y que no descuide a los adultos. La denuncia del sacramentalismo y del ritualismo mágico, característicos de la religiosidad alienante, por no fomentar la confianza en sí mismo y promover el individualismo exagerado, es simplemente 
eliminada. Los obispos tampoco reconocen la existencia de una religiosidad popular paralela a la oficial.

La denuncia del subdesarrollo y de la dependencia es sustituida por la exaltación de los valores sociales, morales y culturales nacionales. Aunque el episcopado reconoce la dominación extranjera, calla la existencia de contradicciones sociales, en concreto, la referencia a las clases sociales y a otras divisiones. El rechazo de la defensa de la propiedad privada como inalienable y absoluto con grave perjuicio del bien común es reemplazado por el reconocimiento de un concepto inadecuado de la propiedad con grave perjuicio del bien común. La denuncia de la falta de unidad social es sustituida por la ausencia de planificación para coordinar la acción social. La responsabilidad en la misión eclesial y, por consiguiente, en sus fallas, en concreto, el descuido de la lucha contra el pecado y la promoción de la liberación, en parte, por un concepto insuficiente de la salvación y de la misión eclesial y, en parte, por miedo a perder privilegios y sufrir persecución, es reemplazada por el reconocimiento de que la Iglesia, "a la vez divina y humana", experimenta los condicionamientos socioeconómicos y culturales del medio social, y por "los laudables esfuerzos en el mejoramiento social de nuestros pueblos", aunque "no se ha logrado contribuir eficazmente [a su] liberación y [...] promoción". La denuncia de la connivencia del episcopado y la nunciatura con la clase opresora, de silenciar la injusticia, de discriminar al pueblo en la designación de obispos y párrocos y de la falta de unidad de criterios y prácticas pastorales es silenciada.

Los señalamientos de las conclusiones de la semana al clero y a la vida consagrada - despreocupación de la realidad nacional, estrecha relación con la clase dominante, afán de lucro, educación clasista, división, paternalismo, clericalismo, marginación del seglar, predicación inadecuada y alta concentración en la zona urbana - y al seglar - dualismo y temor al compromiso político- son desconocidos por los obispos. Al mismo tiempo, estos intentan defenderse con el argumento de que algunos de ellos sí habían defendido al pueblo. Solo se hacen cargo de cierta descoordinación. Luego pasan al ataque y lanzan varias acusaciones contra el clero, la vida consagrada y los seglares. Al clero lo acusan de paternalismo y autoritarismo, de formación y mística sacerdotal deficientes, de ser pocos y de estar mal distribuidos. A la vida consagrada, de falta de compromiso con la realidad salvadoreña, en una velada alusión al origen extranjero de la mayoría de sus integrantes. Y a los seglares, de irresponsabilidad ante el compromiso temporal y la Iglesia, y de pasividad ante el pueblo.

En la segunda parte de su respuesta, la conferencia episcopal reemplaza "La Iglesia: sacramento de salvación para el hombre entero en su historia concreta" por una simple "Reflexión teológica", que abunda en largas disquisiciones sobre la salvación, la Iglesia y la evangelización. Todo para soslayar la constatación de la semana que aseguraba que la Iglesia era vista por el pueblo 
como una fuerza que podía colaborar con su liberación. La constatación tenía graves consecuencias prácticas, de las cuales las conclusiones señalan dos: "La única salvación y liberación prometidas en el Señor y cuya plenitud se nos manifestará al final, ya se están realizando", en la organización de las comunidades eclesiales de base, la participación activa de los campesinos y de las barriadas marginadas en la misión eclesial y la incipiente organización política popular, independiente, del Gobierno y de los partidos políticos tradicionales, lo cual exige "una conversión seria para entregarnos a ellas a través de un compromiso de acción eficaz".

Las conclusiones pastorales de la conferencia episcopal silencian la determinación de la asamblea de no quedarse en las declaraciones, sino de ponerlas en práctica para contribuir eficazmente a la liberación de la realidad. En general, el episcopado timorato suprime todo aquello que le parece radical, al mismo tiempo que adopta una perspectiva triunfalista. De esta manera, suprime las opciones para trabajar por el cambio total y radical de la estructura socioeconómica, cultural, religiosa y educativa capitalista y sus justificaciones ideológicas, para acelerar el proceso de concientización del campesinado, de luchar por su liberación, para llamar a los diversos sectores a apoyar la denuncia de la injusticia y para sostener los centros de promoción campesina y los equipos itinerantes de pastoral, dos elementos cruciales de la evangelización rural. En vez de ello, los obispos solo hablan de corregir las deficiencias del capitalismo. En esa misma línea, matizan el pronunciamiento de la semana a favor de la libre sindicalización rural con el añadido "dentro de los límites de la competencia de la Iglesia”. En consecuencia, silencian el deseo de una liturgia liberadora, no condenan a quienes desde la Iglesia defienden el capitalismo en los medios de comunicación social, ni respaldan el acceso a ellos de las clases populares, ni que el presidente de la comisión episcopal de medios sea un seglar competente, asesorado por un obispo de la capital. En pocas palabras, los obispos rechazan el compromiso directo con la liberación del campesinado, cuya evangelización y organización política ya estaba en marcha.

Aceptan la creación de delegados o ministros seglares, pero solo sería como medida temporal, mientras se supera la escasez de clero. Su desinterés en esta cuestión se manifiesta en pasar por alto su identidad y misión, temas tratados por la semana - encarnado en la comunidad local con la misión de predicar, bautizar, distribuir la comunión y presidir los matrimonios-. Por último, los obispos piden a los superiores de la vida consagrada colaborar en la pastoral de conjunto, pero silencian las propuestas de la semana, que piden revisar el apostolado a la luz de dicha pastoral de conjunto, participar activamente en la vida parroquial y transformar el centro educativo clasista, motivo de escándalo, o cerrarlo. 
El conflicto entre las conclusiones de la semana y la conferencia episcopal puede explicarse por la diferente perspectiva sobre la realidad eclesial salvadoreña. A comienzos de 1970, la conferencia episcopal había hecho su propio diagnóstico de dicha realidad, en la sesión del 12-14 de enero. El planteamiento episcopal evidencia una visión muy particular y totalmente opuesta a la de la semana. Según los obispos, el problema fundamental radica en el clero. El obispo de Santiago de María lo considera relajado, pues había abandonado el traje talar, por tener un espíritu contestatario, por tender al alcoholismo y participar en fiestas populares y profanas. De esta manera, la razón última de la situación eclesial sería la insubordinación abierta del clero contra la disciplina eclesiástica. El obispo de Santa Ana señala la falta de fe y el predominio de lo social sobre lo religioso en el clero como las raíces de la crisis. Por consiguiente, propone una campaña de espiritualización, tal como la que había organizado para el clero de su diócesis, y orar más en las sesiones de la conferencia. El obispo de San Vicente echa de menos la existencia de casas de retiro para el clero y pide más firmeza y coordinación entre los obispos (Conferencia Episcopal de El Salvador [Cedes], Acta 66, 12-14 de enero de 1970).

Movida por estas reflexiones, la conferencia episcopal envía un mensaje confidencial al clero, fechado en San Salvador, el 14 de enero. El documento da por hecho la relajación del clero y señala como causas la falta de una oración mental más fervorosa y el abandono de "la indumentaria eclesiástica" por el "traje campesino, con lo cual no se dan a respetar, ni respetan a las mujeres". El sacerdote, explican los obispos, no debe avergonzarse del traje talar, pues lo defiende, lo conserva y lo blinda contra "ciertas acometidas" externas como el licor, el espíritu contestatario, las fiestas profanas y los espectáculos públicos, sobre todo, el cine, que no es solo diversión, sino también escuela de violencia, pornografía y hedonismo, y "el descoco de la moda femenina". Al respecto, los obispos advierten al clero que

el desnudo aunque no sea propiamente obsceno, sí es provocativo, ante los estímulos somáticos y psíquicos es fuente de tentación ayer, hoy y mañana. Podrá ser ligero atenuante el ad assuetis non fitpassio. Sin embargo, el fomes peccati es siempre el mismo, principalmente en nuestro clima, tanto en la juventud como en el mediodía de la vida; a no ser los misóginos y homosexuales que no reaccionan ante el llamado fuerte del sexo complementario. El peligro, pues, existe. ${ }^{8}$

La Sagrada Congregación para el Clero alaba la intervención de la conferencia episcopal, que juzga necesaria para eliminar aquellas afirmaciones que,

8. Conferencia Episcopal de El Salvador (Cedes), Mensaje Confidencial de la Conferencia Episcopal de El Salvador a los sacerdotes de ambos cleros de su Provincia Eclesiástica, San Salvador, 14 de enero de 1970. 
en directo, contradirían al magisterio universal y a las disposiciones disciplinarias vigentes. No obstante, Roma no está satisfecha, porque encuentra que persisten afirmaciones equívocas. Por lo tanto, exige una nueva revisión que suprima esas ambigüedades. En concreto, la Congregación considera equívocas, por imprecisión teológica, la siguientes afirmaciones: "Es una evangelización [...] que no siempre ha tratado de procurar la liberación total del hombre", "su misión esencial, de la Iglesia, es ofrecer a todo hombre su salvación integral", "la evangelización [...] comprende necesariamente, si es verdadera, todo el ámbito de la promoción humana, si es integral y plena", "Buena Nueva de Salvación que actualiza la liberación integral del hombre en su contexto concreto de oprimido", "línea profética, capaz de cambiar las deficiencias del sistema dominante en el país”, así como las afirmaciones sobre los sacramentos y su pastoral9.

Además, la Congregación juzga erróneas varias propuestas pastorales. En concreto, la promoción del desarrollo integral y del sindicalismo para formar líderes comunitarios que no sean catequistas, sino personas responsables y entregadas a la liberación. La objeción romana rechaza una presunta prolongación directa del ministerio jerárquico en la política. Más de fondo, la Congregación teme que esas propuestas, en nombre de una ambigua liberación total del hombre, reduzcan la misión de la Iglesia a lo temporal y atribuyan a la jerarquía y al ministerio ordenado funciones sociopolíticas. Por lo tanto, rechaza que la jerarquía y el ministerio ordenado adquieran compromisos sociales y políticos, orientados a la liberación integral. Por último, las apreciaciones sobre la realidad social y política del país, así como los juicios sobre su situación religiosa, le parecen ofensivos ${ }^{10}$.

En el área del ministerio, la Congregación manifiesta serias reservas respecto a la figura ministerial del delegado y sus funciones, y respecto a la comisión nacional de pastoral de conjunto. Según ella, delegar habitualmente las funciones del ministerio consagrado al seglar es un contrasentido teológico por confundir el sacerdocio jerárquico con el común, que puede prestarse a actos jurídicos inválidos e ilegítimos. La propuesta de crear una comisión nacional de pastoral de conjunto, conformada por sacerdotes, religiosos y seglares, con metas de corto y largo plazo, sería otra abierta desviación teológica, jurídica y pastoral, porque se le atribuye jurisdicción pastoral sobre otros sacerdotes y superiores religiosos, porque su actividad directiva y ejecutiva implicaría equiparar los carismas, y porque, en la práctica, dirigiría la pastoral ${ }^{11}$.

9. Sacra Congregatio Pro Clerigis, "Acerca de la Pastoral de Conjunto en El Salvador", Acta Romana 11, 2.

10. Ibidem.

11. Ibidem. 


\section{La intervención de Rutilio Grande}

Antes de que los obispos se pronunciaran sobre las conclusiones de la semana, Rutilio Grande advierte a la conferencia episcopal que no solo no podrían neutralizar la semana de pastoral con una declaración, sino que esta "sería lamentable", porque provocaría una confrontación "fatal". Por eso, se arma de valor y se dirige por escrito a los obispos con la expectativa de evitarlo y de abrir un espacio para dialogar y matizar sus ideas, que "ahora brotan apasionadas"12. El documento llegó a la conferencia por medio de Mons. Romero, amigo personal de Rutilio. Este texto, así como dos intervenciones en la conferencia mensual del clero de la arquidiócesis (el 23 de julio y el 5 de noviembre), proporcionan detalles importantes sobre la semana de pastoral e información adicional sobre la Iglesia salvadoreña y, en particular, el clero y los obispos.

Antes de pronunciarse, Rutilio recomienda a la conferencia episcopal discernir con cuidado, para lo cual debía escuchar a personas conocidas por su "buen juicio" y "probada prudencia" y que hubieran asistido a la semana. Sin duda, esta había tenido fallas y el documento final tenía algunas exageraciones, pero había que evitar que "por ciertas expresiones, audaces a juicio de algunos, y por ciertos géneros literarios, como yo los llamaría (vender tal o cual edificio [alusión al lujoso edificio de la nunciatura], etc.), se echasen por tierra cosas totalmente válidas y fundamentales en una pastoral de urgencia y con el carisma particular de la Iglesia de nuestro país". El problema de fondo no era banal, pues la crisis era obra de Dios mismo. Por eso, "bueno sería que con una buena dosis de discreción de espíritus saquemos adelante el carro en buena forma, y ojalá que con la calma de Juan XXIII despejemos el camino ante el que nos hemos visto abocados en fuerza de las circunstancias"13.

A continuación, Rutilio recuerda a los obispos su enorme responsabilidad ante el pueblo salvadoreño que esperaba "algo bueno" de la Iglesia, pues todavía reaccionaba positivamente ante el hecho religioso, "no hay que dormirse ante esta coyuntura", ni replegarse bajo "la cómoda sombra institucional". El desafío planteado por las conclusiones de la semana debía ser enfrentado por todos, los obispos los primeros, que debían proceder con valentía y pronunciar una palabra de aliento para mantener viva la esperanza popular. Resguardarse en "el catolicismo de fachada" dominante era una falsa ilusión, tal como lo demostraba la acelerada urbanización de San Salvador y su periferia. “№ nos hagamos ilusiones! Gran parte de esa gente va entrando más rápidamente de lo que creemos en la gran masa de los descristianizados. Y a medida que vaya avanzando hacia el campo ese ambiente, nuestro campesinado irá entrando" en

12. R. Grande, Representación de la conferencia episcopal de El Salvador, San Salvador, 23 de julio de 1970.

13. Ibidem. 
él. Todavía había tiempo para impedir que el secularismo alcanzara la zona rural, donde vivía la mayor parte de la población salvadoreña. "No nos lamentemos después de haber perdido para la Iglesia la gran parte de nuestro pueblo, si les dimos una religión que no pudieron sostener al primer embate de la vida secular o que no les dio nada para la construcción de su mundo, para la liberación integral de sus personas (en el sentido aceptable del término), en sus derechos inalienables de personas". Si la Iglesia no estaba a la altura de los tiempos, el pueblo la despreciaría y la condenaría ${ }^{14}$.

Las conclusiones de la semana no podían ser descartadas con el argumento de la vida poco ejemplar de algunos sacerdotes, ni con el alegato de que habían sido aprobadas por presión de los universitarios, porque eso era falso. Solo habían participado los dirigentes de la pastoral juvenil urbana y únicamente en las mesas de trabajo. Rutilio no justifica al clero, sino que llama la atención sobre la necesidad de reconocer la validez de la Palabra de Dios en sí misma. Sin duda, la semana era criticable por varias razones. Él mismo hubiera preferido una mejor preparación, mayor representatividad del sector eclesiástico, un estudio más profundo de realidad socioeconómica del país, "a fin de que todas esas tremendas realidades bajaran a la conciencia de muchos que duermen inconscientemente", y una reflexión teológica exhaustiva. También le hubiera gustado participar en la redacción de las conclusiones, pues era miembro de la comisión responsable de su redacción, para que el enfoque fuera más moderado y las afirmaciones más matizadas. Pero por descuido, solo había asistido a la elaboración de una página y media. Pese a todo eso, las conclusiones contenían verdades incuestionables, a las cuales había que "sacar partido al máximo posible [...] para bien de la Iglesia en nuestro país", puesto que "no sin cierta Providencia de Dios se mueven las cosas aunque llenas de las imperfecciones humanas". Por lo tanto, sus críticas no debían ser malentendidas por los obispos, pues "de ninguna manera [pretenden] condenar, sino salvar cuanto sea posible la proposición ajena, como nos enseña un Santo [Ignacio de Loyola], antes de emitir juicios o proceder a acciones"15.

Una vez conocido el parecer de la conferencia episcopal y después de haber representado en privado sin haber sido escuchado, Rutilio se siente obligado en conciencia a contradecir a los obispos, en la reunión del clero del 3 de noviembre, porque "en conciencia [...] no encuentro [...] nada contra la ortodoxia, ni contra la disciplina e instituciones eclesiásticas", "a no ser que se las saque de contexto". Sabe bien que contradecir públicamente a la conferencia "es delicado

14. Conferencia del Rvdo. padre Rutilio Grande, S.J., en la reunión mensual del clero arquidiocesano, martes 23 de julio de 1970.

15. Representación en la Conferencia Episcopal de El Salvador, San Salvador, 23 de julio de 1970; conferencia del Rvdo. padre Rutilio Grande, S.J., en la reunión mensual del clero arquidiocesano, martes 3 de noviembre de 1970. 
en extremo", pero "lo hago llevado de mi propia conciencia y únicamente bajo esta condición he aceptado hablar aquí [...] Lo hago en este foro íntimo y sin ánimo de sensacionalismo ni con ánimo de ofender ni mucho menos de desobedecer, estoy pronto a acatar cualquier decisión de la autoridad en este foro, si yo estuviere en el error". Aun cuando intenta explicarse la reacción episcopal como "una natural reacción contra la radicalización de ciertos juicios valorativos", la condena autoritaria no deja de ser una "lamentable" equivocación, pues no hay error. En cualquier caso, el criterio último lo tenía la realidad de un pueblo oprimido que interpela y exige una palabra de salvación a la Iglesia que, aunque "puede seguir tranquilamente como hasta ahora en una calma y en una falta de sentido crítico y sin discernimiento de espíritu", está llamada a colocarse a su lado, "según la teología de Cristo encarnado, para redimir[lo] y llevarlo a la Resurrección"16.

Contrario al parecer episcopal, la semana no había sido lamentable, ni triste, sino un reflejo veraz de la vida de la Iglesia, "ahí está como un hecho conflictivo que ha causado una crisis, en la que todos estamos implicados". Los participantes en la semana, por razones obvias, y los obispos, por emitir juicios de valor sin fundamento. Ninguno debía perder de vista que Dios mismo había colocado a la Iglesia en la coyuntura de crisis, "una auténtica gracia de Dios" y un llamado apremiante a la conversión. Rutilio descubre en la crisis un signo de los tiempos, es decir, un indicio de que Dios pedía algo más, "porque ningún acontecimiento escapa a esta historia (de salvación), y Dios anda siempre de por medio, aunque se nos haga difícil reconocerlo". La crisis no solo "es el camino de Dios y pasa por la mitad del corazón del hombre [...] Cristo pone al hombre en estado de crisis, que es estado de salvación", sino que, además, "toda la Biblia es una teología de la crisis: una reflexión teológica inspirada acerca de la tensión existencial radical del hombre ante Dios (dimensión vertical) y ante los demás hombres (dimensión horizontal). Dios va llevando a su pueblo hacia la conversión, de crisis en crisis, de caída en caída, de fe en fe". Por lo tanto, había que asumirla sin "esconder la cabeza como el avestruz ante el peligro, ante la dificultad. Una crisis está ahí siempre como un tumor, hay que interiorizarla por la fe, y hay que tratar de superarla". Además, sentencia Rutilio, una institución sin tensiones está muerta. Si la Iglesia estaba en crisis, era porque en ella había vida y espíritu. De momento, las conclusiones habían despertado la conciencia eclesial: "Ya es tiempo que despertásemos de esta realidad dolorosa. ¡Demasiado tardábamos!”, en recibir el concilio ${ }^{17}$.

16. Conferencia del Rvdo. padre Rutilio Grande, S.J., en la reunión mensual del clero arquidiocesano, martes 3 de noviembre de 1970.

17. Ibidem. 
Una de las consecuencias más visibles de la crisis era la división eclesial: "Hay verdaderos grupos antagónicos en nuestras filas". La división no solo había sorprendido, sino que, además, había puesto en evidencia la poca disposición para dialogar: “¡Estamos al desnudo y a campo raso! [...] Parece que todos estamos de acuerdo en que no estamos preparados para el diálogo que tanto propugnamos, y por otra parte somos conscientes de que ese diálogo es en nosotros necesario y urgente, si queremos construir la unidad eclesial". Por lo tanto, la crisis no se superaría con declaraciones, tal como, al parecer, pretendían los obispos. De hecho, ya había suficientes documentos "y comienzan a ser demasiados. Son tan bellos y quién sabe si ineficaces [...] Conclusiones como las de Medellín ahí están clamando al cielo hace tiempo, y casi son letra muerta". Si la Iglesia no pasaba a la acción, corría el grave peligro de convertirse en "una secta de desilusionados hechiceros del cielo" que se esfuerzan por conservar la religiosidad popular para poder seguir viviendo en la tierra. Ante este desolador panorama y en nombre de la fidelidad al Evangelio, Rutilio propone la conversión personal e institucional, esto es, la renuncia a posturas tomadas de antemano para poder emprender un diálogo sincero y humilde, respetuoso del otro y de sus opiniones ${ }^{18}$.

Teológicamente, la declaración de la conferencia episcopal era insostenible, por carecer de fundamento. No solo desconoce el magisterio del Vaticano II y de Medellín, sino que también contradice a Gaudium et spes (66) al afirmar la dualidad de la Iglesia y el mundo. En un falso intento por salvar la trascendencia, el episcopado suprimía el compromiso de la Iglesia con el mundo, necesitado de salvación ( $G S$ 66). Por eso, prescindía de la teología del pueblo de Dios ( $L G 9, G S 32$ ) y afirmaba un individualismo inaceptable. Asimismo, los obispos obviaban Medellín y su profetismo, así como el compromiso con la liberación integral de los pueblos latinoamericanos, lo cual es sorprendente, "porque tratándose de hacer una reflexión desde nuestras realidades lo más apropiado es echar una mano de una reflexión teológica hecha a nivel latinoamericano"19.

Ciertamente, la conferencia episcopal hablaba de liberación, pero no en el sentido de Medellín. Por eso, Rutilio le recuerda que, según los obispos latinoamericanos, la liberación era la respuesta teológica adecuada a los desafíos de la realidad. En abierta contradicción con la visión desarrollista del episcopado y, probablemente, influido por Ellacuría, Rutilio afirma que la situación de injusticia y de opresión no era un mero accidente del desarrollo capitalista, sino el resultado de estructuras injustas, que negaban al pueblo la dignidad de los hijos y las hijas de Dios. "En nuestro país", denuncia Rutilio, "estas estructuras, no sin intervención de decisiones pecaminosas del hombre, presentan un carácter

\section{Ibidem.}

19. Apuntes de Rutilio Grande sobre el documento de la Cedes; Conferencia del Rvdo. padre Rutilio Grande, S.J., en la reunión mensual del clero arquidiocesano, martes 3 de noviembre de 1970. 
de situaciones de pecado". Si se mantienen, es por la opresión y la violencia, a la cual Medellín llama violencia institucionalizada. La única solución a esta situación de pecado estructural, entendido como objetivación del pecado personal y social, es la salvación o liberación de la injusticia. Por eso, la historia del pueblo era "el lugar teológico" de la salvación. El Dios de Jesucristo había despertado al pueblo de su letargo y lo había colocado en "situación de éxodo". Ahora ese pueblo esperaba una palabra de ánimo y de esperanza ante la liberación que se aproximaba. Aunque solo al final de los tiempos, cuando venga el Reino de Dios, se consumará la liberación, era imperativo contribuir a acelerar su llegada sin evadir la responsabilidad. Por eso, el binomio opresión-liberación era susceptible de "una buena interpretación teológica con la enorme ventaja de haber sido pensado en América Latina"20.

En contra del parecer de la conferencia episcopal, Rutilio piensa que solo desde la integración "operativa" de la historia y la trascendencia se podía comprender correctamente la misión de la Iglesia y del sacerdote:

No hay que pensar o imaginar la Historia de Salvación, como si fuera subsistente por sí, en absoluta independencia de la historia humana; como si los hechos de la historia humana fueran indiferentes, y la salvación siguiera otro camino simplemente individual e interno; como si solo hubiera de aparecer al final, a la hora del juicio de la sanción.

La misión de la Iglesia no es diferente a la de Jesús. Por consiguiente, aquella ha de salvar o liberar al mundo empecatado para que los seres humanos se perfeccionen, se desenvuelvan creativamente y crezcan indefinidamente en libertad. Al ser prolongación de la misión de Jesús, la Iglesia también ha de ser profética y condenar, sin miedo a la persecución, "la perversión económica" y la opresión de la humanidad de todos los tiempos, así como la búsqueda de riqueza y de poder político, porque la injusticia niega "la paternidad de Dios sobre todos los hombres, definitivamente sellada en la encarnación". Tal vez pensando en los obispos y su obsesión con la institucionalidad, Rutilio recuerda que Jesús había "proclamado la liberación de la alienación religiosa ritual", hasta el extremo de condicionar la legitimidad del culto al respeto a la humanidad, pues "Cristo recalcó así el carácter provisional, no absoluto, de toda institución humana, tanto de la civil como de las manifestaciones de organización religiosa, juzgándolas por su respeto al hombre, obra de Dios mismo". Por lo tanto, la legitimidad de la religión proviene de su capacidad para crear personas libres. "Precisamente porque Dios es creador y renovador de una humanidad libre, no puede existir

20. Conferencia del Rvdo. padre Rutilio Grande, S.J., en la reunión mensual del clero arquidiocesano, martes 3 de noviembre de 1970. 
legítimamente religión alguna que ayude a esclavizar al hombre por el hombre, ni humanismo alguno que olvide a Dios" ${ }^{21}$.

La necesidad y la urgencia de transformar la realidad empecatada hacen de la cuestión social "la prioridad absoluta" de la misión de la Iglesia. Según Rutilio, todo apostolado, por fidelidad a Jesucristo, debía estar concebido en función de la sociedad. La encarnación no permite vivir el encuentro de la humanidad con Dios al margen del encuentro consigo misma. Por lo tanto, la fe está condicionada por la estructura social y "la acción [...] con finalidad liberadora no puede ser reducida a apéndice ético individual dentro del mensaje y de la vida cristiana. Esto degradaría el carácter del hombre, de la sociedad humana y del mundo, como realidades en que Cristo se ha encarnado para salvarlas, para liberarlas". De este modo, la Iglesia salvadoreña no podía evadir la liberación histórica con el argumento de que era tarea propia de los seglares y no de los sacerdotes. Ciertamente, estos deben anunciar la Palabra de Dios, llamar a la conversión y animar a la comunidad, pero también están llamados a luchar para erradicar el pecado del mundo. La misión sacerdotal y apostólica consiste en hacer presente a Cristo en el mundo y en encaminar a la humanidad hacia Dios, ayudándola a aceptar y cumplir su obligación de transformar el mundo. Pero para ello, el sacerdote debía hacerse presente activamente en esa realidad necesitada de salvación ${ }^{22}$.

De ahí que la concepción del sacerdocio de Rutilio sea muy diferente a la del episcopado. El sacerdote está llamado a "cristificar [sic] el mundo, contribuir en la pequeña medida de sus fuerzas y de la gracia [...] a la realización del plan de Dios que quiere recapitular todo en Cristo". En definitiva, el sacerdote debe seguir a Jesús, pero "sin ser su misión la de un político o la de un agitador social, sin embargo, su actuación, su Palabra, incidió necesariamente en la vida pública, con resonancias claras en política y en las instituciones de su patria". La realización de esta misión sacerdotal exigía, negativamente, abandonar las concepciones preconcebidas y paralizantes de la teología tradicional sobre la misión de la Iglesia y del sacerdocio, y, positivamente, abrirse a la novedad liberadora, adoptar una actitud crítica frente a las propias realizaciones y las del pueblo con la libertad de "la palabra no encadenada" y concebir la vida sacerdotal y la pastoral desde la liberación. No es un simple humanismo, tal como piensan los obispos, sino una consecuencia de la fe, que afirma que "la transformación y progreso del hombre en la historia tiene [...] su definitiva dimensión en la plenitud de Cristo". Tampoco es uno de tantos "ismos", sino la toma de conciencia de las exigencias del mensaje evangélico ${ }^{23}$.

21. Ibidem. 
El clero no era el causante de la crisis, como pensaban los obispos, quizás con la intención de evadir su propia responsabilidad, sino que los sacerdotes "somos más bien víctimas". La formación de la mayoría adolecía de fallos evidentes. La filosofía escolástica no era más que esencialismo cosificante y, en consecuencia, deshumanizante. La teología era poco bíblica, polémica, naturalista y alejada de la realidad humana e histórica. El estilo de vida impuesto a los seminaristas infundía más temor que sentido de la responsabilidad. La pastoral solo se ocupaba de administrar la mayor cantidad de sacramentos posible y de su eficacia casi mágica. Así, pues, la formación no había preparado al clero para enfrentar los desafíos de la realidad y de la Iglesia, según el magisterio conciliar y latinoamericano. La vida del clero, de la cual Rutilio conocía bastante como consejero y director de muchos sacerdotes, era una cuestión que debía tratarse "con sinceridad y aceptando los hechos para analizarlos con humildad y para deducir conclusiones", "sin escándalo farisaico". Se refería, muy probablemente, a que, de hecho, muchos ya vivían el ministerio ordenado en pareja. Por eso, la sugerencia de ordenar para el ministerio a los casados no debía escandalizar, sino que convenía pensarla con serenidad, puesto que "los hechos y las realidades que vemos a nuestro alrededor nos deben llevar a un análisis objetivo y sincero" 24 .

En relación con lo anterior, Rutilio plantea con gran lucidez la crisis de identidad sacerdotal del clero. La seguridad triunfalista del sacerdote tradicional, fundamentada en la anulación del sacerdocio común de los fieles y en la exaltación de la dignidad sacerdotal, hasta el punto de hacer que se sintiera superior a los ángeles y como otro Cristo salvador de almas, representante de Dios en la tierra, había sido cuestionada por el Vaticano II y Medellín. Pero en lugar de aceptar el desafío y ponerse en actitud de búsqueda, el clero había pasado del complejo de superioridad al de inferioridad derrotista.

¡Antes éramos todo, ahora casi nada! Presos de estructuras eclesiásticas anacrónicas; con fama de ricos, cuando los más no lo son, entre la indiferencia general de los de arriba y la desconfianza general de los de abajo. De la eminencia hierática de la casta y de la clase sacerdotal, llena de privilegios, hábitos, títulos y dignidades comenzamos a aterrizar en el humilde valle de la realidad, empezamos a sentirnos hombres iguales a los demás hombres, cristianos iguales a los demás cristianos. ${ }^{25}$

Esta crisis también era un llamado a la comprensión y a la conversión. En consecuencia, Rutilio invita al presbiterio de San Salvador a mirar hacia adelante para superar la crisis de identidad, que tanto desasosiego y sufrimiento causaba.

24. Ibidem; representación en la Conferencia Episcopal de El Salvador, San Salvador, 23 de julio de 1970.

25. Conferencia del Rvdo. padre Rutilio Grande, S.J., en la reunión mensual del clero arquidiocesano, martes 3 de noviembre de 1970 . 
La verdadera solución, dijo, estaba en Dios. Pero para eso había que ser fiel a la gracia y vivir con "el corazón traspasado por Dios". La seguridad es ajena al cristianismo, pues la vida cristiana está jalonada por periódicas crisis purificadoras, que invitan a la conversión. Es decir, estaban obligados a correr "el riesgo y la aventura de vivir la fidelidad en movimiento, en tensión existencial dramática, ¡en crisis!". En la coyuntura de la semana de pastoral, eso significaba enfrentar la oposición del episcopado. Pero si su postura era insostenible, el enfrentamiento abierto no era alternativa, porque "sería absurdo, suicida, estéril" perder el tiempo en "un tira y afloja que no sé cuándo acabaría, desgastándonos inútilmente en luchas intestinas cuando la casa está que arde", porque invocar reivindicaciones cuando había tantas susceptibilidades heridas, haría las heridas más profundas: "No es hora de seguir en lamentaciones ni de seguir varados en la playa, cuando hay verdadera urgencia de lanzarnos pronto a alta mar y a velas desplegadas". Además, el clero se encontraba en clara desventaja frente al poder episcopal ${ }^{26}$.

No obstante esa urgencia, no convenía quemar etapas para acelerar el proceso de reforma de la Iglesia y transformación de la realidad, porque "nada se consigue a saltos y por la mera publicación de documentos si no va por delante una previa mentalización". Eso era, justamente, lo que había ocurrido con el concilio y Medellín. Y ese era también el peligro de las conclusiones de la semana, "aunque de hecho se llegue a conclusiones buenas, es posible que los dirigentes mismos no las hayan asimilado ni se hayan convertido, con lo que habremos tenido un parto más de documentos". De todas maneras, la paradoja persistía:

Comprendo y comparto las justas ansias de muchos que al contacto con nuestra realidad, sienten fiebre de cuarenta grados, iy no es para menos! Y todavía el dolor aumenta más, sabiendo que tenemos los cauces para un actuar eficaz, decisivo y urgente en nuestro país, a la luz de los documentos actuales de la Iglesia; pero nos sentimos frenados por falta de asimilación [...] tanto en los de arriba como en los de abajo. Y la fiebre aumenta al considerar que el tiempo y los acontecimientos vuelan inexorablemente y estamos siendo interpelados cada vez más para dar una respuesta adecuada [...] si es que no queremos traicionar a Cristo y a nuestro pueblo consecuentemente. Hay pues una urgencia existencial. ${ }^{27}$

De todas maneras, había que encontrar una salida, porque la paralización era inadmisible. La alternativa, propone Rutilio, debía ser viable, es decir, había que evitar la polémica infructuosa, la división, que favorecía a la oligarquía y al Gobierno, y el cortoplacismo, pues de lo que se trataba era de "abrir una brecha 
en el Muro de las Lamentaciones y [...] lanzarse a vivir el drama de la fe como historia de liberación hoy". En consecuencia, planteó tomar las coincidencias de las conclusiones de la semana con la declaración de la conferencia episcopal como punto de partida.

\section{La polémica del catolicismo tradicional en la prensa nacional}

La polémica eclesial trasciende a la prensa nacional de la mano del catolicismo tradicional, que la emprende contra la semana de pastoral y sus conclusiones. Su argumentación refleja el pensamiento tradicionalista predominante en un sector influyente de la Iglesia salvadoreña, incluida la mayoría de su jerarquía. El portavoz más conspicuo de esta tendencia es Emilio Simán, un militante de Acción Católica, educado por los jesuitas. El primer artículo, publicado en la prensa nacional el 17 de julio de 1970, pretende desautorizar las conclusiones con el argumento de la falta de representatividad eclesial de la semana de pastoral. Por eso, las conclusiones no podían hablar en nombre del pueblo de Dios, ni de la Iglesia. El clero y los religiosos que habían participado en ella no eran más que "curitas de nueva ola". Algunos de ellos, herejes, y otros, con "tendencias revolucionarias marxistas" 28 . En otros artículos parecidos, Simán denuncia la existencia de sacerdotes contrarios al magisterio, infieles al celibato, descaradamente desobedientes a la jerarquía, profanadores de los sacramentos y apóstoles del odio y de la violencia.

Tampoco los seglares que habían participado en la semana eran representativos, porque los verdaderos no eran universitarios, "aleccionados al estilo belga", una alusión a la labor de varios sacerdotes de esa nacionalidad, que trabajaban en una céntrica zona popular de la capital, sino los católicos de su generación, hombres apostólicos, maduros y comprometidos como él mismo ${ }^{29}$. Estos católicos auténticos, tal como los llama Simán, confiesan un Cristo más divino que humano y una fe revelada y eterna, conciben la Iglesia como remanso de paz frente a la dureza de la vida, exigen fidelidad al magisterio, desean encontrar en el sacerdote a un padre y a un consejero ponderado y, en consecuencia, excluyen la política del ministerio eclesial.

Calificar la realidad nacional de injusta y, por lo tanto, como pecado objetivado, señalar a la jerarquía por su connivencia con la clase opresora y reclamar a la nunciatura el nombramiento inconsulto de los obispos, alusión directa al nombramiento de Mons. Romero como obispo auxiliar de San Salvador, dado a conocer el 21 de junio, le parecían juicios escandalosos. Aquí Simán defiende a Mons. Romero, para quien pide respeto, devoción y cariño por su vida intachable,

28. E. Simán, "Diálogo de un laico. Sal sin sabor", La Prensa Gráfica, 17 de julio de 1970.

29. Ibidem. 
su celo apostólico y sus virtudes humanas y sobrenaturales, todo lo cual, según él, había sido reconocido por Roma al "elevarlo a la dignidad episcopal". En ese entonces, eran amigos y colaboradores cercanos. Naturalmente, rechaza la desautorización que las conclusiones hacían a quienes como él defendían la ortodoxia en la prensa, la destitución del obispo responsable de los medios de comunicación social, la condena de la educación católica por su carácter clasista y el reclamo del ministerio ordenado para los seglares, en particular, para las mujeres ${ }^{30}$.

El sector tradicionalista rechazaba la teología del Vaticano II y de Medellín como doctrina peligrosa, "difundida como moneda buena, pero, en realidad, cargadas de errores doctrinales", que confundían a los fieles. En concreto, contesta la definición conciliar de la Iglesia como pueblo de Dios (Lumen gentium), porque la despojaría de su identidad y la secularizaría y porque, en cuanto cuerpo de Cristo, la Iglesia era más realidad sobrenatural que pueblo. Medellín sería producto del grito revolucionario del clero joven y de la manipulación de teólogos, economistas y sociólogos de izquierda. Los obispos habrían aceptado sus conclusiones apresuradamente y presionados por los teólogos de izquierda, pero sin ánimo de someterse a ellos. Según los tradicionalistas, "no es exagerado afirmar que algunos [teólogos] parecen más sacerdotes de la economía y de la política que de la religión católica y apostólica”, pues prescindían de la revelación al hablar de Cristo y de la Iglesia, cuestionaban la estructura jerárquica de esta última, lo cual no era más que un "delirio de grandeza con carácter pontifical", y habían reemplazado la caridad de siempre por un humanismo natural inaceptable ${ }^{31}$. Así, pues, el sector tradicionalista negaba de manera tajante el magisterio del Vaticano II y de Medellín, pero sin contribuir a definir mejor el concepto de la Iglesia y su misión. En realidad, esto era, porque lo sabían desde siempre. La novedad, en sí misma, era rechazada por juzgarla revolucionaria y, por lo tanto, herética y violenta.

El ataque no se quedó sin respuesta. Al parecer, a petición de Mons. Rivera, Rutilio defiende en la prensa al concilio, al magisterio latinoamericano y a la semana de pastoral. Aunque alaba la sinceridad y la valentía de Simán, no le reconoce autoridad para opinar sobre un acontecimiento al cual no había asistido, ni tampoco sobre el Vaticano II y Medellín, que desconocía. Las conclusiones no pretendían ser la última palabra, sino un material para reflexionar, estudiar y discutir. Sus expresiones concisas, audaces e incluso radicales no debían ser sacadas del contexto de la semana. En su respuesta, Rutilio obvió la polémica cuestión de los ministerios, pero no retrocedió en cuanto al papel del seglar,

30. Ibidem; y E. Simán, "Diálogo de un laico. Piedra de escándalo", La Prensa Gráfica, 22 de julio de 1970.

31. E. Simán, "Rebeldía y contestación”, s. f.; y "Diálogo de un laico. Piedra de escándalo", op. cit. 
porque "de ninguna manera se excluye el que [las mujeres] y otros laicos, en regiones y en circunstancias determinadas, puedan y deban prestar verdaderos servicios ministeriales". En este sentido, se asombra del desconocimiento del Código de Derecho Canónico (1917), que estipulaba que, en caso de urgencia, es decir, ausencia del sacerdote durante un mes continuo, el seglar podía bautizar, distribuir la comunión y presidir el matrimonio ${ }^{32}$.

La buena recepción que tiene su primera incursión en la prensa salvadoreña, lo anima a publicar otros artículos de opinión, en el mismo periódico - "La verdad os hará libres" (agosto de 1970), "Religión: ¿Opio del pueblo?” (24 de agosto de 1970) y "Carta a Centeno" (29 de agosto de 1970) - donde, sorprendentemente, le dan espacio, pues el criterio editorial era, y es, ideológicamente muy estrecho. Es probable que la larga amistad de Rutilio con el jefe de redacción del periódico haya influido. Después de la primera contribución, este lo anima a continuar escribiendo, pero sin insistir en la cuestión social. Rutilio acepta la propuesta no sin advertir "la tremenda urgencia del asunto social"33. El siguiente artículo lo dedicó al significado de la bendición, pero, a la mitad, abandona la perspectiva estrictamente religiosa para hacer una dura crítica social:

Por esos pueblos de Dios pasan las caravanas de todos los políticos en tiempos de elecciones, prometiendo también muchas cosas, y se basan en esta gran mayoría silenciosa, para sus triunfos. Los terratenientes se valen de esta gran mayoría para la mano de obra de sus posesiones. Los intelectuales elucubran teorías y más teorías sociológicas, en sus laboratorios allá en la gran ciudad. Y todos hablamos y hablamos, y aquí esta gran mayoría del pueblo salvadoreño, sin voz, pero con voto [...] espera silenciosa. ${ }^{34}$

Sin embargo, él solo prestó su nombre para proteger la identidad del autor de la serie, el rector del Seminario San José de la Montaña, que no era salvadoreño y corría el peligro de ser deportado por el Gobierno (J. I. Scheifler).

En su breve actividad periodística, Rutilio pretende contribuir a desideologizar términos polémicos. Palabras como cambio, liberación o revolución provocaban desasosiego y angustia por simple desconocimiento, pues las ideologías modernas, según Rutilio, las habían tomado de la Biblia. Por lo tanto, no era el cristianismo el que se las había apropiado de manera ilegítima, sino que,

32. R. Grande, "Diálogos con un laico. ¿Sal sin sabor?”, La Prensa Gráfica, 25 de julio de 1970.

33. Rutilio Grande a Rosalío Hernández, jefe de Redacción de La Prensa Gráfica, 31 de julio de 1970 .

34. R. Grande, “A propósito de una bendición”, La Prensa Gráfica, 24 de agosto de 1970. En mayo, El Mundo publicó la serie de cinco artículos "Violencia y situación social", calzados con el nombre de Rutilio Grande, y reproducidos luego en ECA 262 (1970), pp. 369 y ss. 
más bien, se había olvidado de ellas, con lo cual habían perdido su radicalidad original. El cristianismo, por definición, es revolucionario. No amenaza en la calle con un machete, con "odio en el corazón y sangre en las manos", "a no ser la propia cuando es perseguido en virtud de su fidelidad al Evangelio". El carácter revolucionario del cristianismo se remonta a Jesucristo, líder y liberador, cuya obra debía continuar hasta liberar a toda la humanidad de una explotación y opresión intolerables que, teológicamente, es pecado, raíz y causa de todo pecado colectivo e individual. El dinamismo de la fe nace de la promesa del Reino de Dios, que comienza a construirse aquí y ahora. Si Jesús había enseñado a pedir el reino en la oración al Padre, era para que se instalase en la tierra. Así, pues, la fe es inseparable de la historia de la humanidad. Por lo tanto, Rutilio llamó a aceptar esos términos y a usarlos sin complejo de culpa, ni connivencia. Eso sí, la voz "nuevaolero" debía ser suprimida del lenguaje, porque "todo cristiano es una mezcla válida de todo eso, en sentido recto de los términos, si se identifica plenamente con Cristo de ayer, de hoy y de siempre en un afán dinámico de situarse siempre en su época, sin renunciar a los contenidos sustanciales y eternos del Evangelio, con la mirada siempre inquieta".

La tortura psicológica a la que fue sometido un condenado a muerte por fusilamiento motiva otra denuncia contra la injusta estructura social. Eran miles los que "vagan por ahí, sin trabajo, sin escuela, sin seguridad social y sin el mínimum vital [alusión al concepto acuñado por un intelectual salvadoreño de la década de 1920], abocados a cualquier tragedia y aventura [...] ¡Es tan difícil ser hombre, en estas infraestructuras de injusticia y miseria!". El condenado a muerte por la justicia salvadoreña ilustraba de manera elocuente esa injusticia, que clamaba al cielo. Huérfano desde niño, había sobrevivido en la calle sin educación, ni cuidados. La justicia lo había encontrado culpable de un homicidio, cometido intoxicado por el alcohol, pero para Rutilio esa condena era "causa de tu vida desquiciada y de tantos y tantos casos como el tuyo". Esa sociedad, aparentemente victoriosa y satisfecha con el castigo del criminal, era la más culpable. Aun no había sido castigada, porque la justicia utilizaba medidas diferentes, "para unos 50 centímetros, para otros nada más 40 centímetros y para alguno que otro 100 centímetros". Aunque creía en un "Evangelio fulgurante", Rutilio duda, pues "quién sabe si nuestros corazones están convertidos a un amor sincero y a una civilización auténticamente humana y cristiana. ¡Hay tanta diferencia del espíritu de esos escritos a nuestra realidad nacional!". Había "mucha hipocresía, mucho egoísmo, mucha falsedad y poca autenticidad. Somos muy amigos de leyes y de Evangelios escritos en libros; pero nuestros corazones están muy insensibles al amor, a la justicia y a la verdad" 35 .

35. R. Grande, "Carta a Centeno”, La Prensa Gráfica, 29 de agosto de 1970. 
$\mathrm{Ni}$ siquiera la religión estaba libre de responsabilidad. Por eso, Rutilio la acusó de complicidad directa y activa con esas miserias sociales. Por un lado, justificaba al explotador ante la conciencia del explotado, mientras que, por el otro lado, adormecía al pueblo, al someterlo a la resignación y al evitar que intentase modificar el orden establecido. En la práctica, la sociedad injusta le exigía a la religión ser droga adormecedora, al sacerdote, dedicación exclusiva al culto y a los fieles, a sus devociones ancestrales. Así, estos encontrarían resignación y alivio para sus angustias y pesares, permitidos por Dios para su santificación, y los otros, una humilde aceptación de su posición privilegiada, también querida por Dios. De esta manera, los católicos tradicionalistas encubrían la injusticia y la violencia institucionalizada, mientras acallaban su conciencia con la escrupulosa observancia de las prescripciones religiosas y las caridades. Pero esta era la forma más eficaz de desvirtuar y desacreditar a la religión. Pero la fe, según Rutilio,

nos obliga a un gran compromiso y nos pide luchar para terminar con los desórdenes establecidos y aceptados en todos los niveles desde los particulares hasta los nacionales e internacionales. Nuestra religión no puede estar con ninguna injusticia. El católico tendrá que acusarla, emplazarla y corregirla en la medida de sus posibilidades. ${ }^{36}$

La enseñanza social de la Iglesia, en la que el tradicionalismo católico se escudaba para desentenderse de la realidad, no era opio. Rutilio le recuerda que, según Pío XII, esa enseñanza era obligatoria. Por lo tanto, no podían recibir el cuerpo de Cristo sin antes haber aceptado su doctrina, incluida la enseñanza social. Aducir como excusa para escabullir la responsabilidad la complejidad de la cuestión social y la falta de preparación del pueblo para el cambio, no era más que, de nuevo, según Pío XII, hacerse responsable del radicalismo y del progresismo erróneo. Por consiguiente, la Iglesia debía esforzarse para despertar las conciencias y trabajar para salvar a la persona de todos sus pecados, esto es, de la injusticia, la opresión y la marginalidad. Por eso, la comodidad y el egoísmo se sienten interpelados y reaccionan airados ${ }^{37}$. Rechazar el cambio por considerarlo de izquierda era una tentación, motivada por miedo al "espantajo del comunismo [...] una fachada para defender con un mecanismo de autodefensa individual y colectiva, el más crudo y refinado egoísmo que es tan anticristiano y tan ateo como el más rígido sistema filosófico comunista". Derecha e izquierda, sentencia Rutilio, solo habrá al final de los tiempos, cuando el juicio de la historia separe de manera definitiva, según la verdad de Dios. Una verdad que se encuentra en su Palabra, y dichosos quienes la acepten y ajusten su vida a ella ${ }^{38}$.

36. R. Grande, “Religión: ¿Opio del pueblo?”, La Prensa Gráfica, 24 de agosto de 1970. 37. Ibidem.

38. R. Grande, "La verdad os hará libres", agosto de 1970. 
El 6 de agosto de 1970, festividad del patrono de El Salvador (el divino Salvador del Mundo), en la catedral de San Salvador, Rutilio pronuncia la homilía de la misa solemne, presidida por los obispos y a la cual, según la costumbre, asistía el Gobierno en pleno. En su homilía, Rutilio, inspirado por la escatología, mezcla los motivos tradicionales con los novedosos y se pronuncia por la liberación del pueblo salvadoreño. Las consecuencias de su toma de postura pública son inmediatas, los obispos le retiraron su confianza y vetaron su nombramiento como rector del seminario nacional. Rutilio aguardaba el día "no lejano" en que "podamos echar una bendición amplia a todo el territorio de nuestra patria, después de haberla transfigurado todos sus hijos solidariamente, según la voluntad del Creador. Cuando nos sentemos todos a la mesa del Padre común, cobijados por un techo y beneficiados por los dones de la creación que son para todos los hombres" ${ }^{\prime 3}$.

39. R. Grande, “A propósito de una bendición”, La Prensa Gráfica, 4 de agosto de 1970. 